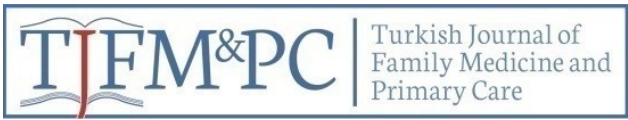

Original Article/Özgün Araştırma

\title{
State and Trait Anxiety Levels of Obese and Overweight Persons
}

\author{
Kilolu ve Obez Bireylerdeki Durumluk ve Sürekli Kaygi Durumu
}

\begin{abstract}
Burcu Doğan ${ }^{*}$, Can Öner ${ }^{2}$
\section{ABSTRACT}

Introduction: Obesity is an important public health problem. The prevelance of anxiety and depression, that negatively affect eating habits, increases in obese individuals. The aim of this study was to determine the frequency of state and trait anxiety in obese and overweight persons and compare them with normal controls. Method: The data of this descriptive and cross-sectional study were obtained from 106 patients followed in the family medicine outpatient clinic. State and Trait Anxiety Inventory was applied to each patient. Participants who had any psychiatric or metabolic disease or who had a history of drug use with psychiatric complications such as corticosteroids were excluded from the study. Descriptive analyses (frequency, percentage, mean, median, Standard deviation and minimum- maximum value) were used. Student's test and ANOVA were used to compare the means, and the relationships between variables were evaluated by Pearson correlation tests. In addition, chi-square test was used to compare the data determined by counting. (p) value was considered significant below 0.05 . Results: Of the 106 participants, $51.9 \%(\mathrm{n}=55)$ were female and $48.1 \%(\mathrm{n}=51)$ were male, with a mean age of $31.6+10.3$ and $33.7+10,3$ respectively. $43.5 \%(n=46)$ of the participants were normal; $25.4 \%(n=27)$ were overweight; $12.3 \%(n=13)$ were obese and $18.8 \%(n=20)$ morbid obese. In our study, when all the participants were considered, the rate of trait anxiety was $55.6 \%(\mathrm{n}=59)$ and the rate of state anxiety was $70.7 \%(\mathrm{n}$ $=75)$. No statistically significant difference was found between the groups in terms of the mean anxiety score $(p=0.65)$ and the mean trait and state anxiety scores $(p=0.582 ; p=0.471)$. Conclusion: The results of the study showed that normal, overweight, obese-morbid obese participants had high trait and state anxietys, but there was no statistically significant difference between these groups. Also no significant relationship was found between anthropometric measurements and trait and state anxiety scores.
\end{abstract}

Keywords: Obesity, anxiety, state anxiety, trait anxiety

ÖZET

Giriş: Obezite önemli bir halk sağllğı sorunudur. Bireyin yeme davranışını olumsuz olarak etkileyen anksiyete ve depresyon sıklıkları obez bireylerde artmışıı. Çalışmanın amacı obez ve fazla kilolu bireylerdeki durumluk ve sürekli kaygı durumunu belirlemek ve normal beden kitle indeksine (BKİ) sahip kişilerle aralarında bir fark olup olmadığını araşıtırmaktır. Metot: Kesitsel tipteki bu çalışmanın verileri aile hekimliği polikliniğinde muayene edilen 106 hastadan elde edilmiştir. Her hastaya "Durumluk ve Sürekli Kaygı Envanteri" uygulanmıştır. Herhangi bir psikiyatrik veya metabolik hastalığı olanlar veya herhangi bir psikiyatrik yan etki profili gösteren kortikosteroid gibi ilaç kullanım öyküsü olanlar bu çalışmanın dışında tutulmuştur. Analizlerde tanımlayıcı ölçütler (sıklık, yüzde, ortalama, ortanca, standart sapma ve en büyükten küçük değer) kullanılmıştır. Ortalamaların kıyaslanmasında Student testi ve ANOVA kullanılırken; değişkenler arası ilişkiler, Pearson korelasyon testleri ile değerlendirilmiştir. Ayrıca, sayımla belirlenen verilerin karşılaştırılmasında Ki-kare testi kullanılmıştır. (p) değeri 0,05 altında anlamlı olarak kabul edilmiştir. Bulgular: Çalışmaya katılan 106 kişiden, \%51,9 $(\mathrm{n}=55)$ 'u kadın, \%48,1 ( $\mathrm{n}=51$ )' $\mathrm{i}$ erkek olup yaş ortalamaları ve standart sapmaları sırasıyla 31,6 $( \pm 10,39)$ ve 33,7 $( \pm 10,3)$ olarak hesaplanmıştır. Katılımcıların \% 43,5 (n=46)'i normal, \% 25,4 $(\mathrm{n}=27)$ 'ü kilolu, \%12,3 (n=13)'ü obez ve \% 18,8 (n=20)'i morbid obez olarak tespit edilmiş̧tir. Çalışmamızda tüm katılımcılar göz önüne alındığında durumluk kaygı oranı \%55,6 $(\mathrm{n}=59)$, sürekli kaygı oranı ise \%70,7 $(\mathrm{n}=75)$ 'dir. Gruplar arasında gerek ortalama kaygı puanı $(\mathrm{p}=0,65)$, gerekse durumluk ve sürekli kayg1 puan ortalamaları $(\mathrm{p}=0,582 ; \mathrm{p}=0,471)$ arasında istatistiksel olarak anlamlı bir farklılık saptanamamıştır. Sonuç: Çalışma sonucunda normal kilolu, obezve morbid obez bireylerde anlık ve sürekli kaygı durumlarının yüksek olduğu ancak gruplar arasında istatistiksel olarak anlamlı bir farklılık olmadığı bulunmuştur. Yine anlık ve sürekli kaygı puanları ile antropometrik ölçümler arasında anlamlı bir iliş̧i saptanamamıştır.

Anahtar kelimeler: Obezite, anksiyete, sürekli anksiyete, durumluk anksiyete

Received Date: 11.06-2019, Accepted Date: 03.12-2019

*1 Sakarya niversitesi Eğitim Araştırma Hastanesi Aile Hekimliği Kliniği

Kartal Dr Lütfi Kırdar Eğiti ve Araştırma Hastanesi Aile Hekimliği Kliniği

Address for Correspondence / Yazışma Adresi: Can Öner, Kartal Dr Lütfi Kırdar Eğiti ve Araştırma Hastanesi Aile Hekimliği Kliniği

E-mail: trcanoner@yahoo.com

Doğan B., Öner C. State and Trait Anxiety Levels of Obese and Overweight Persons TJFMPC, 2020;14 (1): 82-86.

DOI: $10.21763 /$ tjfmpc.693114 


\section{GíRIŞ}

Kayg1, kişinin başına bir tehlike gelebileceği endişesi, huzursuzluk, gerilim, sinirlilik ve korku ile karakterize, hoş olmayan duygusal durum, 'hissedilen şey' olarak tanımlanır. Normal düzeydeki kaygılar birey için pozitif etki ile istek duyma, karar alma, alınan kararları uygulama ve bireylerin performanslarını yükseltme açısından yardımcı olurken; yoğun kaygı durumu kişinin enerjisini verimli bir şekilde kullanmasını, dikkatini ve gücünü yapacağı işe yönlendirmesini engeller. ${ }^{1,2}$ İnsanlarda yaşanılan kaygı süreçleri durumluk kaygı ve sürekli kaygı olarak ikiye ayrılır.

Durumluk kaygı, istenmeyen ve tehlikeli bir durumla karşı karşıya kaldığımızda meydana gelen kaygı düzeyidir. Bireyin içinde bulunduğu stresli durumdan dolayı hissettiği korkudur. Otonom sinir sisteminde meydana gelen bir uyarılma sonucu terleme, sararma, k1zarma ve titreme gibi fiziksel değişmeler, bireyin gerilim ve huzursuzluk duygularını gösterir. Durumluk kaygı seviyesi stresin yoğun olduğu zamanlarda artarken, stres ortadan kalkınca azalır. Tehlike anında geçici, kısa süreli kaygı olarak görülür. ${ }^{3-5}$

Sürekli kaygı durumunda kişiler içinde bulunduğu durumları genellikle stresli olarak algılar ve yorumlar. ${ }^{3-6}$ Ortada kaygılanmak için gerekçe ve ortam yokken veya böyle bir neden var ise olduğunda daha abartılı, orantısız biçimde uzun süreli ve şiddetli kaygı yaşama sürecidir. ${ }^{7}$ Sürekli kaygıda, kişiler tehlikeli ve tehdit edici bir durum yokken bile kendilerini tehdit ortamındaymış gibi algılar ve bunun sonucunda da hoşnutsuzluk ve mutsuzluk hisseder. Sürekli kaygı seviyesi yüksek olan bireylerin kolaylıkla incinmeleri ve karamsarlığa bürünmeleri mümkündür. Bu bireyler durumluk kaygıyı da diğerlerinden daha sık ve yoğun bir şekilde yaşarlar. ${ }^{4}$

Sürekli kaygı, bireyler arasında değişiklik gösteren bir kişilik özelliğidir. Sürekli kaygısı yüksek olan bireyler, düşük olanlara göre stres yaratan durumları çok daha tehlikeli ya da tehdit edici olarak algılama ve daha yoğun durumluk kayg1 reaksiyonları ile tepkide bulunma eğilimindedir. ${ }^{4}$ İnsanlarda meydana gelen kaygı sürecinin uzaması, gelecek kaygısı ile ne yapacaklarına karar verememelerine, başlarına bir şey gelecekmiş gibi yersiz duygulara kapılmalarına yol açmaktadır. ${ }^{3}$
Günümüzde önemli bir halk sağlığı sorunu olan obezite, bireylerin gerek fiziksel ve gerekse mental sağlıklarına olumsuz etkilerde bulunmakta ve yaşam kalitelerini azaltmaktadır. Güncel çalışmalar obeziteyi psikosomatik boyutu olan bir hastalık olarak ele almakta ve bu hastalığın tedavisi için multidisipliner yaklaşımı önermektedir. ${ }^{8}$ Değişik çalışmalarda obez bireylerde depresyon ve anksiyete belirtilerinin yüksek olduğu bildirilmektedir. ${ }^{9}$ Çalışmamızın amacı normal, kilolu, obez ve morbid obez bireylerde durumluk ve sürekli kaygı durumu belirlemek ve aralarında bir fark olup olmadığını araştırmaktır.

\section{YÖNTEM}

Kesitsel tipteki çalışmanın verileri 01 Temmuz 2018 - 10 Ağustos 2018 tarihleri arasında Sakarya Üniversitesi Eğitim ve Araştırma Hastanesi Aile Hekimliği Polikliniğinde muayene edilen ve testleri yapmayı kabul eden 106 hastadan elde edilmiştir. Çalışma öncesinde tüm katılımcıların yazılı onamları alınmıştır. Çalışma grubunun BKİ (kg/m2) ve Türkiye'ye özgü bel çevresi değerlerinin sınıflaması, Türkiye Endokrinoloji ve Metabolizma Derneğinin Obezite Tanı ve Tedavi Kılavuzundaki sınıflama baz alınarak yapılmıştır. ${ }^{10}$ Her hastaya uluslararası kabul gören ve uygulama kolaylığı olan "Durumluk ve Sürekli Kaygı Envanteri” poliklinik muayeneleri sırasında veya sonrasında kişinin sözlü onamı alındıktan sonra uygulanmıştır. Herhangi bir psikiyatrik veya metabolik hastalığı olan veya kortikosteroid gibi psikiyatrikyan etki riski olan ilaç kullanım öyküsü olanlar çalışma dışı tutulmuştur.

Katılımcıların durumluk ve sürekli kaygı durumları Spielberger ve arkadaşları tarafından 1970 yılında geliştirilen ve Öner ve arkadaşları tarafından 1983 yılında Türkçe güvenirlik ve geçerliliği gösterilmiş "Durumluk ve Sürekli Kaygı Envanteri" ile belirlenmiştir. Envanter yirmi maddeden oluşan Durumluk Kayg1 Ölçeği ile yirmi maddeden oluşan Sürekli Kaygı Ölçeği olmak üzere toplam kırk maddeden oluşmaktadır. Durumluk Kaygı Ölçeği, bireylerin belirli bir anda belirli koşullarda kendisini nasıl hissettiğini betimlemesini, içinde bulunduğu duruma ilişkin duygularını dikkate alarak maddeleri cevaplamasını gerektirir. Sürekli Kaygı Ölçeği ise bireyin genellikle kendisini nasıl hissetmesi gerektiğini belirtir. Durumluk Kaygı Ölçeği, maddelerinde ifade edilen duygu ya da davranışlar, bireyin içinde bulunduğu durumu hissetme derecesine göre: (1) hiç, (2) biraz, (3) çok, (4) 
tamamıyla gibi oluşan şıklardan birini işaretleyerek cevaplandırılır. Sürekli Kaygı maddelerinde ifade edilen duygu davranışları ise sıklık derecesine göre: (1) hemen hiçbir zaman, (2) bazen, (3) çok zaman ve (4) hemen her zaman şeklinde cevaplandırılır. Ölçekten elde edilen 36-41 arası değerler kayg1 düzeyi normal olarak değerlendirilirken, 41 ve üzeri puanlar yüksek kaygı seviyelerini, 36 ve altı düşük puanlar düşük kaygı seviyelerini göstermektedir. 5,6

Çalışma verileri SPSS 21.0 paket programında analiz edilmiştir. Analizlerde tanımlayıcı ölçütler (sıklık, yüzde, ortalama, ortanca, standart sapma ve en büyükten küçük değer) kullanılmıştır. Ortalamaların kıyaslanmasında Student testi ve ANOVA kullanılırken, değişkenler arası ilişkiler, Pearson korelasyon testleri ile değerlendirilmiştir. Ayrıca, sayımla belirlenen verilerin karşılaştırılmasında Ki-kare testi kullanılmıştır. (p) değeri 0,05 altında anlamlı olarak kabul edilmiştir.

\section{BULGULAR}

Çalışmaya katılan 106 kişiden, \%51,9 (n=55)'u kadın, \%48,1 (n=51)'i erkek olup yaş ortalamaları sirasiyla $31,6+10,3$ ve $33,7+10,3$ olarak hesaplanmıştır. Katılımcıların \% 43,5 (n=46)'i normal, \% 25,4 (n=27)'ü kilolu, \%12,3 (n=13)'ü obez ve \% 18,8 (n=20)'i morbid obez olarak sınıflandırılmıştır. Katılımcıların sosyodemografik özellikleri tablo1'de verilmiştir. Tablo takip edildiğinde normal gruptan obez ve morbid obez grubuna gidildikçe yaş ortalamasının arttı̆̆ görülmektedir. Yine evli katılımcı oranları kilolu, obez ve morbid obez grupta normal gruba göre anlamlı olarak fazladır. Obez ve morbid obez grubun gelir ve eğitim düzeyi diğer iki gruba göre anlamlı olarak düşüktür.

Gruplar arasında gerek ortalama kayg1 puanı $(\mathrm{p}=0,136)$, gerekse durumluk ve sürekli kayg1 puan ortalamaları $(\mathrm{p}=0,286 ; \mathrm{p}=0,797)$ arasinda anlamlı bir farklılık saptanamamıştır (Tablo 2). Çalışmamızda tüm katılımcılar göz önüne alındığında durumluk kaygı oranı \%55,6 ( $\mathrm{n}=59)$, sürekli kaygı oranı $\% 70,7 \quad(n=75)$ olarak saptanmıştır.

Tablo 1: Çalışma grubunun sosyodemografik özellikleri

\begin{tabular}{|c|c|c|c|c|}
\hline & $\begin{array}{c}\text { Normal } \\
\% 43,4(n=46)\end{array}$ & $\begin{array}{c}\text { Kilolu } \\
\% 25,4(n=27)\end{array}$ & $\begin{array}{c}\text { Obez-Morbid obez } \\
\quad \% 31,1(n=33)\end{array}$ & $\mathbf{p}$ \\
\hline Yaş & $28,3 \pm 8,6$ & $33,2 \pm 9,4$ & $38,1 \pm 10,8$ & 0,000 \\
\hline Kadın & $50,0(23)$ & $44,4(12)$ & $60,6(20)$ & 0,434 \\
\hline Evli & $50,0(23)$ & $74,4(20)$ & $75,7(25)$ & 0,020 \\
\hline Çalışan & $71,7(33)$ & $55,5(15)$ & $60,6(20)$ & 0,380 \\
\hline Sigara kullanan & $42,2(19)$ & $51,9(14)$ & $31,3(10)$ & 0,170 \\
\hline Alkol kullanan & $11,1(5)$ & $7,4(2)$ & $3,1(1)$ & 0,425 \\
\hline Düzenli spor (+) & $20,5(9)$ & $7,4(2)$ & $9,1(3)$ & 0,198 \\
\hline Asgari ücret üstü gelire sahip & $86,9(40)$ & $85,1(23)$ & $57,5(19)$ & 0,031 \\
\hline 12 yıl ve üstü eğitimi olan & $54,3(25)$ & $48,1(13)$ & $24,2(8)$ & 0,009 \\
\hline
\end{tabular}




\begin{tabular}{|l|c|c|c|}
\hline \multicolumn{5}{|l|}{ Tabılo 2: Katılımcıların BKİ göre kaygı durum değerlendirmeleri } \\
\hline & Durumluk Kaygı Puanı & Sürekli Kaygı Puanı & Kaygı Puanı \\
\hline Normal & $40,9 \pm 5,0$ & $43,2 \pm 7,7$ & $42,1 \pm 4,1$ \\
\hline Kilolu & $40,6 \pm 4,9$ & $45,5 \pm 7,6$ & $43,2 \pm 4,5$ \\
\hline Obez-Morbid obez & $41,9 \pm 6,1$ & $44,1 \pm, 9$ & $43,2 \pm 5,5$ \\
\hline
\end{tabular}

Tüm grup ele alındığında katılımcıların beden kitle indeksleri ile durumluk $(\mathrm{r}=0,146 ; \mathrm{p}=0,136)$, sürekli $(\mathrm{r}=0,25 ; \mathrm{p}=0,797)$ ve ortalama $(\mathrm{r}=105 ; \mathrm{p}=0,286)$ kaygı puanları arasında anlamlı bir korelasyon gösterilememiştir. Durumluk ve sürekli kaygı varlığı ve beden kitle indeksi arasındaki ilişki tablo 3 'te gösterilmektedir.

\section{TARTISMA}

Çalışma sonucunda üç grup arasında sosyoekonomik değişkenlerden yaş, medeni durum, gelir ve eğitim düzeyi arasında anlamlı farklılıklar saptanmıştır. Ülkemizde yapılan çalışmalarda obeziteyi belirleyici en önemli nedenlerin yaşlanma, diyabet ve hipertansiyon varlığı, yaşanılan çevre, sosyal durum, düşük eğitim düzeyi, fiziksel inaktivite olduğu gösterilmiştir. ${ }^{10}$ Öte yandan çalışmamızdaki sonuca paralel olarak evli bireylerde obezitenin arttığını, eğitim düzeyi ve gelir seviyesi ile obezitenin ters ilişkili olduğunu gösteren birçok çalışma vardır. ${ }^{11}$

Çalışma sonucunda tüm grup ele alındığında durumluk ve sürekli kaygı durumlarının bir hayli yüksek olduğu ancak gruplar arasında anlamlı bir farklılık olmadığ görülmüştür. Öte yandan kaygı puanları ve BKİ arasında anlamlı bir ilişki saptanmamıştır. Obezitenin bireyin fiziksel, duygusal ve sosyal sağllğı ve yaşamı üzerindeki etkileri bilinmektedir. Obezitenin genç erişkinlerde kontrol gruplarına kıyasla zihinsel stres için bir risk oluşturduğu gösterilmiştir. ${ }^{12}$ Bir başka çalışmada ise obez bireylerde duygusal ve metabolik bozuklukların birliktelikleri ele alınmış ve bu durum "metabolik ruh hali sendromu" olarak tanımlanmıştır. ${ }^{13}$ Obez bireylerdeki zihinsel bozuklukların en sık görüleni ve önemlisi travma sonrası stres bozukluğudur; sonrasında sirasıyla anksiyete bozukluğu, herhangi bir duygu durum bozukluğu ve majör depresif bozukluğu gelmektedir. ${ }^{14}$
Kırk dört ülkede yapılmış bir çalışmada anksiyete prevalansı \%0,9 ile \% 28,3 arasinda bildirilmektedir. Metodolojik farklilıklar düzeltildikten sonra küresel anksiyete prevalansı $\%$ 7,3 olarak saptanmıştır. Çalışma sonucunda cinsiyet, yaş, kültür, çatışma ve ekonomik durum ve şehircilik gibi önemli faktörlerin ülkeler arasındaki prevalans farklılığının en büyük nedenini oluşturduğu görülmüştür. ${ }^{15}$ Obezitenin duygu durum ve anksiyete bozuklukları geliştirme ihtimalinde yaklaşı \% 25'lik bir artışa neden olduğu, bu korku, endişe ve rahatsızlıkla baş etme yollarından birisinin de aşırı yeme olduğu ileri sürülmüştür. ${ }^{14,16}$ Çalışmamızda durumluk ve sürekli kaygı düzeyleri ile BKİ arasında bir ilişki gösterilememiş olmakla beraber obez ve morbid bireylerde yüksek oranda sürekli ve durumluk kaygı saptanmıştır. Her ne kadar sürekli kayg1 durumu ve obez bireyler arasinda duygusal beslenme arasında bir ilişki gösterilmiş olsa da tüm gruplarda yüksek düzeylerde durumluk ve sürekli anksiyete düzeyi olması; obezitenin yanı sıra coğrafya, kültürel farklılıklar ve soyoekonomik farklılıkların; bireyin manevi durumu ve ruhsal iyilik halinin ciddi karıştırıcılar olarak karşımıza çıktığını ve bu nedenlerle kıyasın zorlaştığını düşündürmektedir. ${ }^{15,17,18}$

Çalışma sonucunda her üç grubun da ( normal, kilolu ve obez morbid obez) durumluk ve sürekli kaygı durumlarının yüksek olduğu ancak gruplar arasında anlamlı bir farklılık olmadığ görülmüştür. Yine durumluk ve sürekli kaygı puanları ile antropometrik ölçümler arasında anlamlı bir ilişki saptanamamıştır. Kaygı düzeyinin yeme davranışı üzerindeki önemli bir etkisi olduğu değişik çalışmalarda gösterilmiştir. ${ }^{19} \mathrm{Bu}$ nedenle obez bireylerde yeme kontrolü açısından anksiyete durumunun değerlendirilmesi faydalı olabilir. Çalışmanın çok küçük bir grupla ve hastanede yapılmış olması anksiyete puanlarının yüksek çıkmasına etki etmiş olabilir. Sonuçları genele yansitırken bu kısitlılık dikkate alınmalıdır. Öte yandan sosyal parametrelerin her birinin biri 
üzerinde ve anksiyete üzerindeki olası etkileri, karıştırıcı faktör olarak etki ediyor olabilir.

\section{KAYNAKLAR}

1. Yiğit $Y$, Dilmaç $M$, Deniz ME, Hamarta E. Sürücülerin Sürekli ve Durumluluk Kaygılarının Bazı Değişenler Açısından İncelenmesi; Uluslararası Avrasya Sosyal Bilimler Dergisi 2011; (2):4

2. Charles D. Spielberger, State-tait anxiety inventory, The Corsini Encylopedia of Psychology. 2010-107

3. Endler NS, Kocovski NL. State and triat anxiety revisited. Anxiety Disorders 2001;15: 231-235

4. Öner N, Le Compte A. Durumluk-Sürekli Kayg1 Envanteri El Kitabı.1.Baskı. İstanbul: Boğaziçi Üniversitesi Yayınlarl;1983.p.1-26.

5.Öner N. Türkiye'de Kullanılan Psikolojik Testler.3.Baskı. İstanbul: Boğaziçi Üniversitesi Yayınlar1;1997.p.13-27.

6.Özgüven E. Psikolojik Testler.4.Baskı. Ankara: PDREM yayınlar1, Sistem Ofset;2000.p83-120.

7.Ocaktan M E, Keklik A, Çöl M. Abidinpaşa Sağlık Oağında Çalışan Sağlık Personelinde Spielberg Durumluk ve Süreklii Kaygı Düzeyleri. Ankara Üniversitesi Tip Fakültesi Dergisi 2002;55 (1): 21-28.

8. Resch M, Haasz P, Sido Z. Obesity as psychosomatic disease. European Psychiatry 1998;13(4):315.

9.Simon GE, Von Korff M, Saunders K, Miglioretti DL, Crane PK, van Belle G, Kessler RC. Association between obesity and psychiatric disorders in US adult population. Arch Gen Psychiatry 2006; 63:824-830.

10.TEMD.Obezite Tanı ve Tedavi Kılavuzu.8.Baskı.Ankara: Miki Matbaacılık San. ve Tic. Ltd. Şti ;2019.p.21-25.

11. Tzotzas T, Vlaavas G, Papadopoulou S, Kapantais E, Kaklamanou D, Hassapidou M. MArital status and educational level associated to obesity in Greek aduts: data from thenational epidemiological Survey. BMC Public Health 2010;10:732.
12. Dreber H. Reynisdottir S. Angelin B. Tynelius P. Rasmussen F. Hemmingsson E. Mental distress in treatment seeking young adults (18-25 years) with severe obesity compared with population controls of different body mass index levels: cohort study. Clinical Obesity. 2017; 7 (1):1-10

13. Mansur RB. Brietzke E. Mclntyra RS. Is there a "metabolic-mood syndrome"? A review of the relationship between obesity and mood disorders. Neuroscience \& Biobehavioral Reviews. 2015, 52:89-104

14. Scott KM. McGee MA. Wells JE. Oakley Brownw M.A. Obesity and mental disorders in the adult general population. Journal of Psychosomatic Research. 2008, 64 (1):97-105

15. Baxter AJ. Scott KM. Vos T. Whiteford HA. Global prevalence of anxiety disorders: a systematic review and meta-regression. Psychological Medicine. 2013, 43 (5):897-910

16.Abramson E.E Wunderlich R.a. Anxiety, fear and eating: a test of the psychosomatic concept of obesity. J Abnorm Psychol. 1972,79 (3):317-321

17.Schneider K.L. Appelhans B.M. Whiled M.C. Oleski J. Pagoto S.L. Trait anxiety, but not trait anger, predisposes obese individuals to emotional eating. Appetite 2010,(55) 3,701-706

18. Steiner LM: Zaske S. Durand S. Molloy M. Arteta R. Spiritual factord predict state and trait anxiety. J.Relig Health 2017, 56 (6):1937-1955

19.Ruderman AJ. Obesity, anxiety amd food consumption. Addictive Behaviors 1983, 8(3):235242 